\title{
Confirmation of Sclerotinia sclerotiorum as the causal agent of stem rot of stock in Korea
}

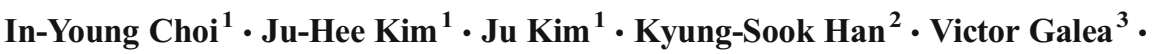 \\ Hyeon-Dong $\operatorname{Shin}^{4}$ (D)
}

Received: 7 February 2017 / Accepted: 11 April 2017 / Published online: 20 April 2017

(C) Australasian Plant Pathology Society Inc. 2017

\begin{abstract}
Typical symptoms of Sclerotinia stem rot were observed in commercial crops of stock in several districts in Korea during the 2012-2013 and 2013-2014 winters. Based on morphological characteristics and phylogenetic analysis of internal transcribed spacer sequences, the pathogen was identified as Sclerotinia sclerotiorum. This is the first report of Sclerotinia sclerotiorum infection of stock in Korea.
\end{abstract}

Keywords Matthiola incana $\cdot$ Sclerotinia sclerotiorum . Sclerotinia stem rot $\cdot$ Stock

Stocks (Matthiola incana), belonging to the family Brassicaceae, are an annual-biennial ornamental crop that are traditional favourites widely used throughout the world and are popular as cut flowers and garden bedding plants (Uota and Harris 1964). Available in a variety of colours, many cultivars are heavily scented and used in floristry. In Korea, stocks are mostly grown during winter in polyethylene tunnels to meet the high demand for the cut flower trade for school ceremonies in February and March.

Hyeon-Dong Shin

hdshin@korea.ac.kr

1 Jeollabuk-do Agricultural Research and Extension Services, Iksan 54591, South Korea

2 Horticultural \& Herbal Crop Environment Division, National Institute of Horticultural and Herbal Science, Wanju 55365, South Korea

3 School of Agriculture and Food Sciences, The University of Queensland, QLD 4343, Australia

4 Division of Environmental Science and Ecological Engineering, Korea University, Seoul 02841, South Korea
Sclerotinia sclerotiorum is a devastating plant pathogen, and more than 60 names have been used to refer to disease caused by it including stem rot, cottony rot, watery soft rot, crown rot, blossom blight and perhaps most commonly, white mold (Purdy 1979). The fungus infects over 400 species of plants worldwide including important crops and numerous weeds (Boland and Hall 1994). Sclerotinia sclerotiorum poses a threat to dicotyledonous crops such as soybean, edible dry bean, chickpea, peanut, dry pea, lentils, sunflower, oilseed rape and various vegetables, but also monocotyledonous species such as tulip and onion (Boland and Hall 1994; Bolton et al. 2006).

During the 2012-2013 winter, typical symptoms of Sclerotinia stem rot were observed in commercial crops of stock (cv. Spark) in Suwon $\left(37^{\circ} 12^{\prime} 04^{\prime \prime N} ; 127^{\circ} 00^{\prime} 11^{\prime \prime E}\right)$, Korea. About $20 \%$ of plants withered or died before harvest, causing considerable economic losses. Symptoms included stem necrosis and withering of leaves, followed by crown rot and wilt a few days afterwards (Fig. 1a). White cottony growth of the fungus was observed on dead plants (Figs. 1b and c) and the immediate soil surface, particularly where relative humidity was high. Black sclerotia of 2 to $7 \mathrm{~mm}$ in diameter developed within the mycelium (Fig. 1d). Similar symptoms were also found in stock crops in Iksan

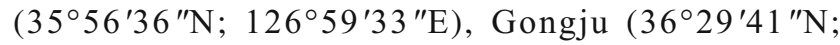
$\left.127^{\circ} 02^{\prime} 03^{\prime \prime} \mathrm{E}\right)$, and Taean $\left(36^{\circ} 44^{\prime} 27^{\prime \prime} \mathrm{N} ; 126^{\circ} 16^{\prime} 57^{\prime \prime} \mathrm{E}\right)$, Korea, during the following winter (2013-2014). Voucher specimens were deposited with the Korea University herbarium (KUS). Isolations from surface-disinfested stem pieces onto potato dextrose agar (PDA) consistently yielded white, fluffy colonies, and later produced plentiful numbers of black sclerotia (Fig. 1e). The fungus was morphologically identified as Sclerotinia sclerotiorum (Bolton et al. 2006).

An isolate used for molecular analysis and pathogenicity testing was deposited with the Korean Agricultural Culture Collection (Accession No. KACC47726). Fungal DNA was 
Fig. 1 Stem rot caused by Sclerotinia sclerotiorum on stock (cv. Spark). a. Stems and leaves were infected, devastating the whole plants. b and c. Symptoms of stem rot showing white cottony molds. d. Close-up view of a dead stem. e. Ten-day-old colony of S. sclerotiorum on a potato dextrose agar. Note the sclerotia formed on the margin of colony
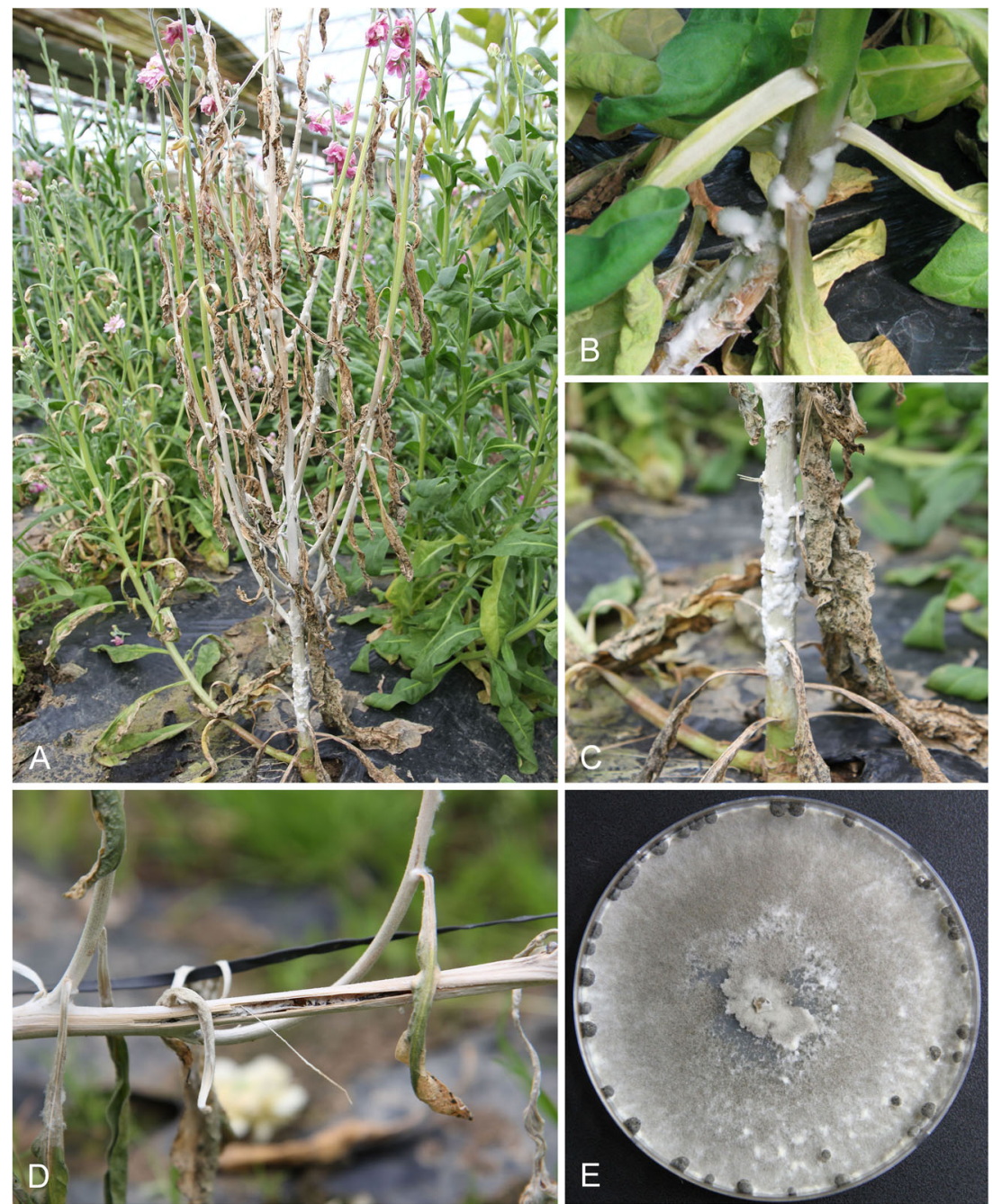

extracted with a DNeasy Plant Mini Kit (Qiagen Inc., Valencia, CA). The complete internal transcribed spacer (ITS) region of rDNA was amplified with the primers ITS1/ ITS4 and sequenced (White et al. 1990). The possible identity of the isolate was established by comparing their ITS sequences with those in the GenBank database (National Center for Biotechnology Information [NCBI] US National Institute of Health, Bethesda, MD, USA; http://www.ncbi. nlm.nih.gov/BLAST). Phylogenetic analysis of the ITS sequence data was conducted by means of a neighborjoining (NJ) method using MEGA, ver. 6.0 (Tamura et al. 2013) and the sequence distance was calculated under the Tamura-Nei parameter model. Bootstrap values were obtained from 1000 replications to determine the support for each clade.

The resulting sequence of 558 bp was deposited in GenBank (Accession No. KJ614567). A BLAST search revealed that sequences of the Korean isolates were identical with those of S. sclerotiorum (e.g., KF859933, KJ614564,
KF859932, and JN013184). The phylogenetic tree showed that the fungal pathogen isolated from stocks was closely related to S. sclerotiorum and formed a well-supported clade that was sister to a clade consisting of Sclerotinia spp. (Fig. 2).

A pathogenicity test was achieved by placing PDA plugs $\left(9 \mathrm{~mm}^{2}\right)$ from a 7-day-old culture grown on PDA onto the stems of healthy pot-grown stocks (cv. Spark) near the soil line. Five plants inoculated with agar blocks and five plants sprayed with sterilized water served as controls. Treated and control plants were individually covered with polythene bags to maintain $100 \%$ relative humidity for $24 \mathrm{~h}$, and maintained in a greenhouse at 16 to $20{ }^{\circ} \mathrm{C}$ and relative humidity $>90 \%$. After four days, all inoculated stems became discolored, soft, watery, and covered with white mycelia, whereas control plants remained symptomless. Sclerotinia sclerotiorum was consistently re-isolated from the symptomatic tissue, and was morphologically identical to the original isolate. The pathogenicity tests were repeated twice with similar results, fulfilling Koch's postulates. 
Fig. 2 Molecular phylogenetic analysis of Sclerotinia sclerotiorum and related taxa obtained from GenBank by neighbor-joining method based on the ITS sequences. Bootstrap values are shown for branches with $>60 \%$ support. The isolates in this study are shown in boldface

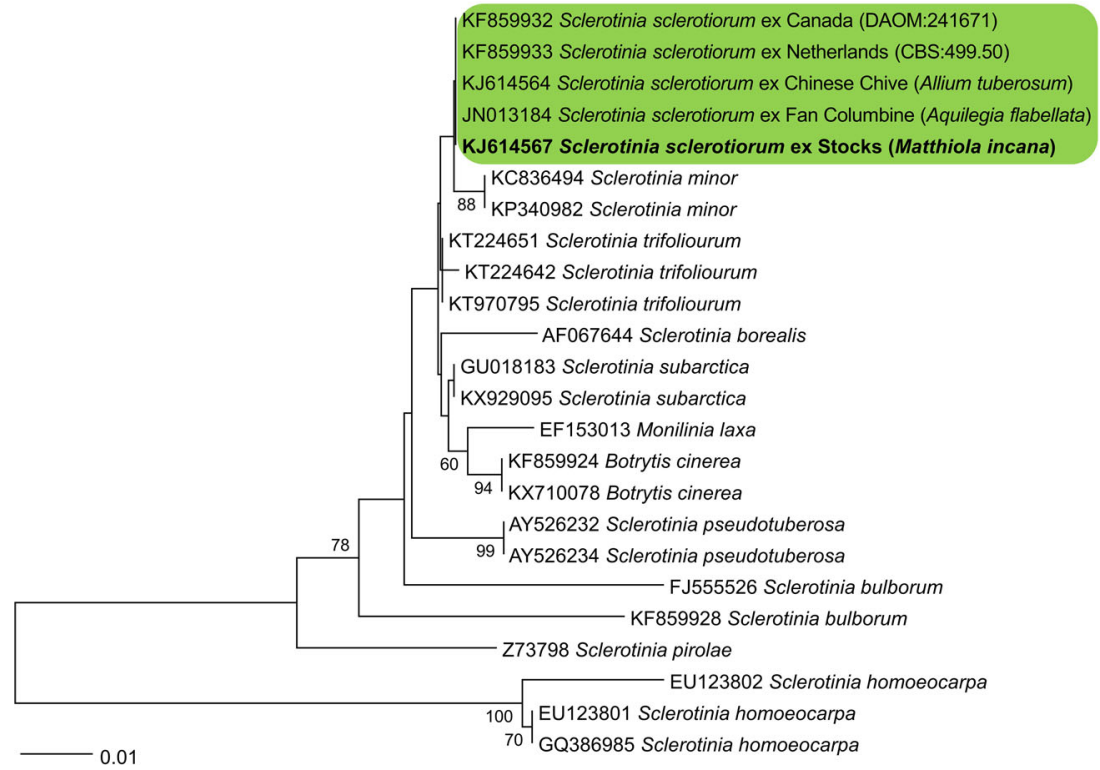

Currently, Sclerotinia stem rot of stocks caused by $S$. sclerotiorum has been recorded from the United States, Scotland, Greece, South Africa, Australia and New Zealand (Farr and Rossman 2017). In 1991, this disorder was listed as a previously undescribed disease of stocks in Korea without descriptions of symptoms and the causal fungus (Lee 1991). Subsequent to that initial (un-verified) record, there have been no published reports of the disease on this crop. To our knowledge, this is the first well-founded report with fulfillment of Koch's postulate for the occurrence of Sclerotinia stem rot of stocks in Korea. According to our observations in affected commercial plots, low temperature, high humidity, poor ventilation and continuous cultivation in non-heated polyethylene tunnel cultivation systems encourages the incidence of Sclerotinia stem rot of stocks in Korea.

Acknowledgments This study was carried out with the support of the "Cooperative Research Program for Agricultural Science \& Technology Development (Project No. PJ0124192016)”, Rural Development Administration, Republic of Korea.

\section{References}

Boland GJ, Hall R (1994) Index of plant hosts of Sclerotinia sclerotiorum. Can J Plant Pathol 16:93-108

Bolton MD, Thomma BPHJ, Nelson BD (2006) Sclerotinia sclerotiorum (lib.) de Bary: biology and molecular traits of a cosmopolitan pathogen. Mol Plant Pathol 7:1-16

Farr DF, Rossman AY (2017) Systematic mycology and microbiology laboratory, ARS, USDA. http://nt.ars-grin.gov/fungaldatabases/. Accessed 7 Jan 2017

Lee YH (1991) Diseases and insect pests of agricultural crops found in 1991. Res Report Rural Develop Admin 33:1-15

Purdy LH (1979) Sclerotinia sclerotiorum: history, diseases and symptomatology, host range, geographic distribution, and impact. Phytopathology 69:875-880

Tamura K, Stecher G, Peterson D, Filipski A, Kumar S (2013) MEGA6: molecular evolutionary genetics analysis version 6.0. Mol Biol Evol 30:2725-2729

Uota M, Harris CM (1964) Quality and respiration rates in stock flowers (Matthiola incana) treated with N6-benzylaminopurine. US Agr Mktg Serv AMS 537:1-8

White TJ, Bruns TD, Lee SB, Taylor JW (1990) Amplification and sequencing of fungal ribosomal RNA genes for phylogenetics. In: Innis N, Gelfand D, Sninsky J, White TC (eds) PCR protocols and applications - a laboratory manual. Academic Press, New York 